\title{
La construcción de la identidad latinoamericana. Una aproximación hermenéutica a la visión de Leopoldo Zea.
}

\author{
Víctor Manuel Guerra ${ }^{1}$ \\ Este artículo busca presentar los aportes intelectuales de Leopoldo Zea \\ en la construcción de una filosofía latinoamericana, que defina lo que el \\ latinoamericano es para la historia y oriente lo que debe ser para la construcción \\ de una sociedad más justa en Latinoamérica.
}

This article aims to present the intellectual contributions of Leopoldo Zea in the construction of a Latin America philosophy, one that defines what to be Latin American means for history and one that orients what it must be for the construction of a more just society in Latin America.

\section{Introducción}

Este trabajo quiere ser un aporte a la construcción de la identidad de los pueblos latinoamericanos, específicamente en el área de la construcción de la filosofía latinoamericana. Son muchos y muy valiosos los aportes intelectuales que hombres y mujeres de este continente han dado en esta temática. No obstante, la construcción de la identidad y de la filosofía propia de este continente, siguen siendo una tarea inacabada.

Uno de los filósofos más enriquecedores de la construcción del pensamiento filosófico y cultural en Latinoamérica ha sido Leopoldo Zea (1912-2004)². Y será a él a quien se recurra, a efectos de entresacar de su pensamiento, algunos elementos para fundamentar esta incesante búsqueda de la identidad latinoamericana.

Por ser salvadoreño quien lleva a cabo esta investigación, interesa también saber qué es lo que piensan y han dicho los intelectuales salvadoreños respecto de esta temática. De ahí que se tome a Alberto Masferrer (1868-1932), como referente nacional respecto de lo que se ha escrito en torno a la temática.

Como afirma Andrea Díaz, "la identidad no es alguna clase de esencia a descubrir, sino algo que está dado independientemente de nuestra actitud." 3 Por tanto,

1. Profesor de Biblia, en la Universidad Don Bosco.

2. De Leopoldo Zea se tomará su obra monumental La esencia de lo americano, Editorial Pleamar, Buenos Aires, Argentina, 1971.

3. Díaz Genis, Andrea, La construcción de la identidad en América Latina, Editorial Nordan-Comunidad, Montevideo, Uruguay, 2004, p. 21. 
se sigue lo que dichos autores presentan respecto de la construcción de la identidad latinoamericana y de la construcción de un pensamiento filosófico propio.

Tomando en cuenta que el ser humano es en realidad un despliegue de riqueza y variedad de contenido, no puede existir una idea uniforme de lo que el latinoamericano es, como dice Díaz, “por necesidad ontológica, no puede existir una sola idea de ser humano, porque ser humano es ser distinto. La historia de las ideas de los seres humanos, es una reinterpretación continua de lo que somos. En este sentido, el rescate del pasado no es una evocación de lo perdido, sino una re-presentación, una recuperación, una revivencia. Sin historicidad no habría pluralidad de ideas de un ser humano." 4

En esta perspectiva, tiene importancia, lo que históricamente hemos pensado los seres humanos nacidos en esta parte del mundo, respecto de lo que somos y el proceso seguido en la construcción cultural latinoamericana. De ahí que afincamos el concepto de identidad, en la idea que ésta, "es una construcción que se relata, pero que implica tanto la lectura del pasado, como la apertura hacia un proyecto." ${ }^{\circ}$ De ahí que la verdad que se nos impone al hablar de identidad no es una verdad fáctica sino una verdad simbólica que nos abre una multiplicidad de significaciones dentro de un contexto social y cultural. ${ }^{6}$

\section{La visión de Leopoldo Zea respecto de la conciencia de lo americano}

\subsection{Lo bárbaro como condena latinoamericana}

Para Leopoldo Zea, entender América latina tiene que ver con la historia real, que a través de los siglos, ha venido incorporando una visión de conjunto del mundo entero, ya que no se puede vivir aislado del resto del mundo. De ahí que, "América latina sea incomprensible sin su contrapartida, la América sajona; pero a su vez, toda la América sería incomprensible sin el viejo mundo que la había incorporado a su historia."7

El filosofar latinoamericano ha conservado una característica fundamental que le diferencia cualitativamente del resto del mundo en la forma de hacer filosofía. En esta línea, "a diferencia de la llamada filosofía universal, tiene como punto de partida la pregunta por lo concreto, por lo peculiar por lo original en América. Sus grandes temas los forman preguntas sobre la posibilidad de una cultura americana; preguntas sobre la posibilidad de una filosofía americana; o preguntas sobre la esencia del hombre americano." De ahí que la pregunta fundamental de la filosofía latinoamericana tenga su principio y fundamento en la conciencia misma de lo accidental del ser humano americano. No obstante,

4. Díaz Genis, Op.Cit., p. 25.

5. Ibídem, p. 27.

6. Cfr. Ibídem, p. 27.

7. Zea Leopoldo, La Esencia de lo Americano, Editorial Pleamar, Buenos Aires, Argentina, 1971; p. 8.

8. Zea, Op. Cit., p. 15. 
un ser humano que no ha sido reconocido por el europeo, con una alteridad propia, con una esencia propia y una historia propia. Eso puede explicar mejor la preocupación del latinoamericano ilustrado, por ser reconocido e incorporado más allá de los umbrales del quehacer filosófico y cultural europeo.

Esto constituye, desde mi punto de vista, una de las trampas más sofisticadas que la cultura indoeuropea haya impuesto a la latinoamericana. Es una trampa cultural y más en concreto, ideológica, porque han tenido que pasar casi cuatro siglos, desde el descubrimiento de América, hasta poco más allá de la independencia de las colonias americanas de las coronas ibéricas, para descubrir, que la esencia misma del americano es sin lugar a dudas, la misma del español, portugués, inglés, francés, holandés, etc. Es decir, el falso problema representado con el monumental problema de la pseudohumanidad del indígena americano. Cosa que condicionó y condenó al americano mismo, a cientos de años de traumatismo psicológico en su concebirse a sí mismo, como un ser humano de segunda categoría. Y, tuvo que pasar más de cuatro siglos para que, hasta muy recientemente, se descubriera que todo era una trampa ideológica de dominación imperialista. Zea nos lo dice de la siguiente manera:

La pregunta por la peculiaridad de la cultura y el hombre de América tiene como punto de partida esta conciencia de lo accidental [...] El americano, a diferencia del europeo nunca se ha sentido universal. Su preocupación ha sido, precisamente, una preocupación por incorporarse a lo universal, por insertarse en él. Y aunque parezca una paradoja, esa misma pregunta por lo que le es peculiar, es una pregunta que tiende al conocimiento de lo que tiene de universal, esto es, de común con todos los hombres. La peculiaridad buscada es la de su humanidad, la de aquello que le hace ser un hombre entre hombres; no el hombre por excelencia, sino el hombre concreto, el hombre de carne y hueso que es, y sólo puede ser. El hombre en cualquier lugar del mundo, con independencia de su situación o, mejor dicho, a causa de esa misma situación, que es lo peculiar a todos los hombres. Este sentido de la peculiaridad del hombre en América que acaba siendo lo propio de todos los hombres. ${ }^{9}$

Ahora bien, tuvieron que pasar cientos de años para que el americano descubriera que no es ni más ni menos que un hombre y que "lo concreto, la diversidad de lo concreto, lejos de hacer imposible la esencia de lo humano lo hace real." 10 En este itinerario es que el ser humano americano se ha desarrollado a través de los siglos y ha descubierto, que los problemas que plantea la filosofía americana sobre el ser del hombre americano son problemas impuestos por la mal llamada filosofía universal; es decir, por el pensamiento europeo y occidental. ${ }^{11}$ De ahí que lo que el filósofo hispanoamericano realizara, todo fuera en función del

9. Zea, Op.Cit. p.16.

10. Op.Cit. p. 17.

11. Cfr. Op.Cit. p. 20. 
filósofo europeo. Por tanto, no vio otra cosa que lo que los europeos veían en América: inmadurez, minoría de edad, primitivismo y barbarie. ${ }^{12}$

Ejecutada la independencia política de las colonias americanas de las coronas española y portuguesa, surge la necesidad de la búsqueda y concreción de la independencia cultural de las mismas ex colonias españolas. Es en este marco, que los iberoamericanos descubrieron en el positivismo, la filosofía que ofrecía las herramientas para el logro de dicho objetivo. No obstante, esto fracasa, porque las ex colonias española y portuguesa, no logran la tan ansiada independencia cultural, sino que por el contrario, se concreta una nueva dependencia de una potencia americana, cuya voracidad es igual o superior a los antiguos imperios. Y, en ese sentido, peor al anterior imperio español:

El positivismo fue la filosofía con la cual los iberoamericanos trataron de arrancarse la herencia ibera que consideraban un obstáculo para incorporarse al mundo moderno; un instrumento de su sajonización. Instrumento que, a la larga, fracasa. Viene, entonces, otro tipo de reacción: la de defensa frente a la América que ha iniciado su expansión en el mundo, incluyendo su expansión en América latina. La Norteamérica del destino manifiesto, las discriminaciones y la política del "garrote". La Norteamérica de los grandes negociantes que imponen tiranos en América latina que cuiden de sus intereses. Esta es la Norteamérica que simbolizó Rodó en la figura de Calibán: el materialismo, frente a la que se alza la figura de Ariel, encarnada en la América latina, la América de la cultura y el espíritu. ${ }^{13}$

Sigue, por tanto, la búsqueda de aquello que pueda poner a Iberoamérica en la vía de la superación del ser mismo iberoamericano; no para llegar a un estadio en el que se pueda dominar a los demás, sino aquel lugar, aquel puesto propio en la historia, que permita tomar las riendas de la propia historia. En esta perspectiva, Zea nos presenta parte de un discurso que el filósofo norteamericano Waldo Frank, pronunciara en Madrid, en 1930, en el que afirma que hay gran necesidad de articular esfuerzos conjuntos de las Américas, la sajona y la ibera, para encaminar al ser humano de estas regiones al encuentro de la historia. En esta línea, este autor afirma en su mensaje que:

Necesitamos uno del otro. Pero a fin de ayudarnos mutuamente, debemos aprender a ayudarnos a nosotros mismos, o sea a conocernos a nosotros mismos. Conociéndonos a nosotros mismos conoceremos también la esencia de otros hombres, lo que de común tenemos con ellos. Descubriendo nuestro ser, habremos descubierto elementos que son de América, que armonizan con lo que otros hombres, en otras partes de América, igualmente empeñados en descubrirse a sí propios están aprendiendo y necesitan."14

\footnotetext{
12. Cfr. Op.Cit. p. 25.

13. Op.Cit. pp. 26-27.

14. Ibidem, p. 29.
} 
Y el camino a seguir tiene que estar orientado desde lo concreto, desde el hic et nunc. Ir a lo universal, lo abstracto, pero sin olvidar nunca lo concreto. Éste debe ser también el camino de nuestra filosofía, como afirma Zea, retomando una idea de Antonio Caso: una filosofía que atienda a lo universal, pero partiendo del hombre concreto, que es cada hombre en nuestro caso, el hombre concreto es el mexicano, el argentino, el chileno, el salvadoreño, etc., para de ahí deducir lo que tiene de común, como parte de la cultura iberoamericana, americana y universal [...] Por eso hay que volver los ojos a lo que nos es más inmediato: a nuestras costumbres y nuestras tradiciones, a nuestras esperanzas y nuestros anhelos, a lo que somos de verdad. ${ }^{15}$

De ahí que haya que hacer filosofía y reflexión filosófica desde nuestros propios condicionamientos, y sin la preocupación de hacer filosofía universal. Porque haciendo filosofía desde nuestras propias circunstancias, el adjetivo "universal" caerá por su propio peso. En esta línea, Zea nos dice que "no basta alcanzar una verdad americana; es menester, además, tratar de alcanzar una verdad válida para todos los hombres aunque de hecho no pueda lograrse. No hay que considerar lo americano como un fin, sino, por el contrario, como un límite y punto de partida para un fin más amplio. De aquí la razón por la cual todo intento de hacer filosofía americana, tendrá que fracasar. Hay que intentar hacer pura y simplemente filosofía, que lo americano se dará por añadidura.”16

Por ello, como afirma Arturo Ardao: “la historia de la filosofía en América cobra para nosotros los americanos, un interés fundamental. Si no lo tiene como revelación de doctrinas o sistemas originales (...), lo adquiere en cambio, como expresión de nuestro espíritu en su historicidad personalísima: en sus ideas y circunstancias que han protagonizado su desenvolvimiento." ${ }^{17}$ Esto permitirá el logro de una meta que por ahora es sumamente importante en el desarrollo de las ideas americanas, es a saber, la meta última: "conocer el puesto del hombre y la cultura americanas en lo universal"18.

Como es bien sabido, existen en América, dos culturas eminentemente diferenciadas, una la sajona y otra la ibérica. Pero ¿por qué razón existen dos culturas, tremendamente distintas y opuestas en América? Ante esta realidad, Leopoldo Zea, retomando una idea de Vianna Moog, afirma que hay un punto de partida de ambas culturas; que aunque ambas sean europeas, también son de corte distinto, son dos actitudes religiosas las que están de fondo; una orientada hacia el individualismo y la otra que se orienta hacia el personalismo:

Espíritu que se hace patente en la misma actitud religiosa que sirve de punto de partida de una y otra cultura en esa expansión: el calvinismo en su expresión puritana en Norteamérica y el catolicismo misionero

15. Cfr. Zea, Op.Cit., pp. 34-35.

16. Ibidem, pp. 35-36.

17. Ibidem, p. 39.

18. Ibidem, p. 42. 
en la América ibera. Actitudes religiosas que son, a su vez, expresión, la primera, del individualismo moderno que ve al mundo en función con el individuo que es el eje de la nueva concepción del mundo; y el personalismo, con un sentido más cristiano y comunal del ibero [la segunda]. Actitudes que señalan, a su vez, la relación de este hombre con los hombres y culturas indígenas de América. ${ }^{19}$

De ahí que, tanto lo que conocemos como cultura anglosajona como la cultura ibera, ambas en América, se hayan visto obligadas a actuar y pensar en función de esa acción que se ha presentado anteriormente. Por ello, la filosofía que ha surgido de esta actitud pragmática en una y otra América se caracteriza por su tendencia hacia una acción inmediata. Como nos lo afirma Zea, la filosofía norteamericana, fiel a la tradición imperialista de la cultura de la cual era originaria, se orientó hacia el dominio, cada vez más amplio de la naturaleza. La iberoamericana, por su parte, también fiel a su origen cultural, se orientó hacia el mundo de la ética y la cultura; es decir, se orientó hacia el mundo de la ética y la política como instrumento de acción concreta. ${ }^{20}$

No obstante, como nos lo dice Leopoldo Zea, existe una diferencia clave entre los tipos de individualismo que se dan en América; asimismo, sus expresiones son diametralmente opuestas. La primera, es decir, el individualismo sajón, hipoteca parte de su libertad en aras de conseguir mayores niveles de seguridad. En cambio, al individualismo latinoamericano, lo que le importa es destacarse como individuo, a tales niveles que se llega a la anulación de los demás. En el mejor de los casos, ese anulamiento de los demás se expresa en una invisibilización de los otros. En el peor caso, se encuentra la anulación sistemática del otro en su humanidad física, un otro que no es aceptado como alteridad. La mayor expresión de esta actitud está en el caudillaje, de la que América latina tiene muchos ejemplos:

La diferencia del individualismo sajón y el individualismo ibero. El sajón ha tejido el conjunto de relaciones sociales necesarias para alcanzar una relativa seguridad [...] que tanto necesita para dedicarse exclusivamente al logro de los bienes en los cuales finca su felicidad. Para el logro de esta seguridad el individuo cede un mínimo de su libertad para alcanzar a cambio un máximo de seguridad. Lo importante es aquí la defensa y seguridad de los estancos que representa cada individuo como miembro de la sociedad. Una sociedad cuya meta es el individuo mismo. Entre los pueblos de origen ibero la individualidad tiene otro sentido: el de personalidad. Aquí lo que importa es destacarse sobre los otros, hacer de los propios fines los fines de los otros. El individuo, lejos de respetar los estancos de los otros individuos, se extiende, crece en ellos. A su vez los otros, cuando no poseen la personalidad anhelada, hacen de las grandes personalidades su propia personalidad, se incorporan a 
ellas, se extienden haciendo de los fines de que ellas persiguen sus propios fines. De esta manera, unos y otros se complementan y dan origen a esas formas de convivencia que hemos llamado comunidades. Expresión de este tipo de convivencia propia de los pueblos iberos es el caudillaje. Caudillaje que es como el polo opuesto de las instituciones liberal-democráticas de los anglosajones. ${ }^{21}$

De ahí que los productos de ambas individualidades fueran tremendamente distintos. La sajona, con un desarrollo económico y político sumamente cualificados y diversificados con la presunción de dominio imperialista mundial, objetivo conseguido después de la supremacía militar demostrada tras resultar vencedora en dos guerras mundiales. Y la otra, la iberoamericana, con productos inacabados tanto en lo político como en lo económico, dando la impresión de que el producto terminado aún sigue siendo una tarea pendiente. No obstante, la cultura en Latinoamérica, "como toda cultura, se encuentra en una etapa de transición que no puede ser vista como signo de inmadurez."22

¿Y cuál es la raíz de todo esto? Leopoldo Zea afirma que esto tiene su raíz en aquéllos que fueron los sujetos de la colonización, cuya orientación y objetivo superior son diametralmente opuestos; por lo que los resultados experimentados son coherentes con los sujetos de dicho hecho: "Los colonizadores iberos en América buscan en el continente, la ampliación del mundo del cual se han hecho paladines en Europa. Su principal preocupación es hacer de esta América otra España o Portugal, esto es, otra Europa Cristiana. Los colonizadores de la América sajona no; estos buscan en este continente una tierra virgen, nueva, sin historia en la cual, cada individuo pueda empezar como si nada estuviera hecho."23

De ahí que sean la civilización y la barbarie, los extremos entre los cuales se agite la vida política iberoamericana, más concretamente hispanoamericana. La meta, lo que se anhela ser, y lo que se es. La forma de convivencia que se anhela alcanzar, frente a la que se ha heredado. La convivencia apoyada en la razón y la que en último término, recurra a la fuerza, a la violencia. Violencia que tiene una rica gama de expresiones, desde las más evidentes hasta las más ocultas. En este marco, Zea afirma que el individuo hispanoamericano, para cambiar la realidad de su forma de vida que es fruto de la herencia española y amerindia usa sin complicación el recurso de la violencia:

A la violencia recurre el hispanoamericano para transformar la realidad que le ha tocado en suerte. Dispuesto a hacer de su mundo un mundo nuevo, moderno, una nación moderna, amputa violentamente su pasado, reniega de la herencia recibida, y se entrega a la tarea de remozar su propio ser, negando lo que ha sido para ser algo completamente distinto: un hombre moderno. $Y$ en este remozamiento,

21. Ibidem, p. 62.

22. Ibidem, p. 48.

23. Ibidem, p. 56 . 
aunque parezca contradictorio, dispuesto a acabar con un pecado que considera bárbaro, primitivo, actúa con la misma violencia que actuaría ese bárbaro y primitivo que quisiera dejar de ser. Hombres que alzan su voz contra el primitivismo y la barbarie no se detienen una vez presentada la oportunidad de lograr lo que consideran su extermino, en utilizar métodos que mucho tienen de ese primitivismo y barbarie que se quieren trascender. ${ }^{24}$

Y, la única forma que se puede trascender esa fatídica realidad es por medio de la educación. Sólo educando, formando a los iberoamericanos en los principios que hacen de las comunidades entidades civiles, se podrá hacer de los mismos hombres libres, demócratas capaces de realizar esa forma de gobierno en el que el pueblo, es el principio y fin. No antes. Antes no podrá hacerse otra cosa que obligar al pueblo a seguir el camino de lo que supuestamente se cree que es su propia liberación. Cosa que al final de cuentas se revertirá contra el mismo pueblo y tendrá sus niveles de expresión en la violencia social, que ya ha adquirido carta de ciudadanía en América latina. Es por esta realidad que Latinoamérica constituye históricamente un mundo de zozobra e inseguridad. Zea nos lo dice de la siguiente manera:

Las comunidades iberoamericanas constituyen un mundo casi primitivo, inseguro, en el que cada individuo se ve obligado a luchar por su seguridad limitando la de otros o descansando en la que los mejores pueden ofrecerle. Mundo inseguro, lleno de zozobras. Un mundo en el que las relaciones de convivencia tienen aún su origen en formas primitivas de parentesco o amistad. Sociedad sin ciudadanos, comunidad más o menos amplia de parientes o amigos. Sociedad en la que se busca eludir cualquier formalidad que impide esa relación directa, concreta, entre individuos. Sociedad cuyas leyes y legislaciones no hacen sino encubrir situaciones de hecho que han sido originadas por voluntades concretas. Sociedad en la cual la maquinaria burocrática es casi siempre eludida por esa institución tan característica en los pueblos iberoamericanos, la "coima" o la "mordida. ${ }^{25}$

No obstante, los esfuerzos hechos en función de ir cualificando el espíritu latinoamericano, desde la perspectiva de grandes intentos de cualificar la educación de los pueblos, han hecho que ahora se vislumbre un cambio de perspectiva respecto de la auto concepción del latinoamericano. En esta línea Zea nos dice que el "latinoamericano se comprende ahora a sí mismo, no como un ente extraño, distinto, peculiar y ajeno a los otros hombres, sino como un hombre entre sus semejantes. Sus esfuerzos, sus luchas, le han llevado a encontrarse con otros hombres que, como él, se esfuerzan por incorporarse a la tarea de construir un futuro, tarea que no puede ser vista ya como exclusiva de un determinado grupo de hombres, pueblos o culturas."26 
Aquí es donde encuentran eco los discursos y las ideas en torno a un nuevo ser latinoamericano, un espíritu integrador de razas, integrador de sangre y espíritu; donde lo que en definitiva va a salir es la raza definitiva, la raza síntesis, la raza integral, hecha con el genio y con la sangre de todos los pueblos $\mathrm{y}$, por lo mismo más capaz de verdadera fraternidad y de visión realmente universal. Raza cósmica no como expresión racial, propiamente dicha, sino como expresión de comunidad de intereses en su más alta esencia cultural. Síntesis de cultura para la cual las diferencias raciales carecerán de importancia y harán posible la síntesis de sangre. ${ }^{27}$

Este espíritu es por fin admitido por las nuevas generaciones en Latinoamérica. Vestigio de ello fue lo evidenciado por Humboldt, quien como dice Zea, corregirá la página de otros autores que han visto nada más que dependencia y un espíritu copista y quizá hasta plagiario de la Europa desarrollada: "El buen prusiano Humboldt corregía las columnas del mal prusiano De Pauw. La América y sus hombres no eran ni mejores ni peores que cualquier otro continente y cualquier otro tipo de hombres. Simplemente eran distintos, pero no inferiores."28

\subsection{La identidad perfilada: La nueva cultura hispanoamericana}

Si algo ha de caracterizar las expresiones del pensamiento latinoamericano, este algo será su extremada preocupación por la realidad que le es propia; en la que sus diversas expresiones han obligado al latinoamericano a dar urgentes soluciones a los múltiples problemas que le plantea. Tres largos siglos de coloniaje, en los que las metrópolis, España y Portugal, habían acostumbrado a los latinoamericanos a soluciones prestadas, les obliga, repentinamente, a buscar urgentes substitutos de esas soluciones:

El hombre iberoamericano se enfrentará, de inmediato, a los problemas que plantea su incorporación a ese mundo nuevo en marcha hacia el progreso. $Y$ en este enfrentamiento se preguntará, en primer término, sobre su propia capacidad para tomar y seguir tal camino. Pregunta sobre su humanidad y sobre las posibilidades que le puede ofrecer el mundo que le ha tocado en suerte vivir. $Y$, como resultado de este enfrentamiento, la seguridad sobre su propia humanidad, sobre su ser hombre, un hombre, entre hombres, ni más ni menos que cualquier otro hombre; y la seguridad, de las posibilidades que le ofrece el mundo de que es parte. Seguridad que le hace enfrentarse a su metrópoli para discutir y destruir los argumentos esgrimidos por ésta para someterlo, para arrancarle sus riquezas y los frutos de su trabajo. Destrucción de argumentos y afirmación de sí mismo que le lleva a la lucha por su emancipación política frente a metrópolis que no han sabido crear un verdadero imperio dentro del cual todos sus hombres no fuesen sino motores de grandeza común. ${ }^{29}$

27. Cfr. Ibidem, p. 100.

28. Ibídem, p. 113.

29. Ibídem, p. 122. 
Después de la independencia política de las colonias iberoamericanas de las coronas española y portuguesa, surge una interminable lucha fratricida de las mismas élites dominantes. Lo que puede catalogarse como un triunfo del desorden en toda Latinoamérica. Es el espíritu anárquico el que se enseñorea en la casi totalidad de Hispanoamérica y de la que sólo escapa el espíritu práctico de los herederos de Portugal, el Brasil. Lucha que hace pensar en un mal que debe anidar en la propia mente y alma del hispanoamericano. Un mal heredado, propio de la España que dio cultura a esta América. Un mal que ha de ser desarraigado como resultado de una nueva emancipación, la mental, que cumpla y haga posible no sólo la política, sino la económica y cultural para todos los pueblos de Latinoamérica. ${ }^{30}$

Preguntas sobre una humanidad y una realidad natural que no se sabía por qué razón eran siempre rebajadas. Preguntas sobre una humanidad regateada una y otra vez como justificación de lo que se consideraba el natural predominio de los metropolitanos sobre los nacidos en estas tierras.

Las nuevas naciones que surgirán del imperio español no parecen dispuestas a sostener las injusticias creadas por los peninsulares. El nuevo orden deberá descansar en un equitativo reparto de sacrificios y beneficios. Lo que naciones, como la mexicana, exigen a la metrópoli, también están dispuestas a concederlo a sus propios miembros. De ahí que en el marco de la independencia de México, el prócer independentista Hidalgo y Costilla, sabe que para subsistir como nación independiente será menester fortalecer a todos los miembros, de la sociedad mexicana. Y, por tanto, elevar el nivel de vida de todos sus grupos, de todas sus clases, es ineludible. Por ello, hay que poner fin a la expoliación que se ha llevado a cabo durante más de tres siglos; por ello ordena que se ejecute la devolución de las tierras a los pueblos indígenas; que "se entreguen a los referidos naturales las tierras para su cultivo, pues es mi voluntad que su goce sea únicamente de los naturales en sus respectivos pueblos." 31 Es importante recordar que la independencia es, en realidad algo más que un simple cambio de gobernantes; se trata de un cambio social, de una restitución de bienes, a aquéllos que se les ha usurpado durante tantos siglos, la raza indígena o los autóctonos de esta parte del mundo.

En esta perspectiva, Zea trae a cuenta otro ejemplo mexicano con el presbítero Morelos, quien además de coadyuvar a llevar a cabo la independencia del Virreynato de la Nueva España, desarrolla un movimiento de justicia social, iniciado con la abolición de la esclavitud en México y la devolución de las tierras a sus antiguos propietarios, los indígenas. Inicia así el proceso de reforma agraria que busca, evitar que se promuevan los latifundios, para que no se genere riquezas extraordinarias a unos pocos. Sino que por el contrario, los beneficios que la tierra trae con su riqueza, sea beneficioso para todos y todas. En esta perspectiva, Zea es de la idea que José María Morelos, seguirá la línea del cura 
Miguel Hidalgo de hacer del movimiento de independencia un movimiento de justicia social que permita a todos los grupos sociales del país colaborar en la marcha de la nación con sus mejores esfuerzos. ${ }^{32}$

Morelos, siguiendo a Hidalgo, ha decretado también la abolición de la esclavitud y de las castas y la devolución de las tierras a los indígenas. Por ello, ordena también lo que podría ser la primera expresión de la siempre discutida reforma agraria de estas Américas, el reparto de las grandes haciendas para que nadie se enriquezca en lo particular y todos queden beneficiados en lo general. Todos deberán ser iguales, dispuestos a realizar sacrificios semejantes si han de percibir beneficios también semejantes. No más castas, no más discriminaciones, sólo una gran raza, una sola nación, la americana. No se nombran en calidades de indios, mulatos y castas, sino todos generalmente americanos. Que la esclavitud se prescriba para siempre, y lo mismo la distinción de castas, quedando todos iguales y sólo distinguirá a un americano de otro, el vicio y la virtud. Americanos frente a peninsulares, americanos frente a europeos. El imperio emancipado de la España y sus limitados intereses. Un imperio en que se ponga fin a las injusticias cometidas por sus creadores y no sean substituidas por otras. ${ }^{33}$

Así como Hidalgo y Morelos en México, Bolívar con visión profética, en la Gran Colombia, hacía ver a sus contemporáneos, que los latinoamericanos no podrían ser respetados y tomados en cuenta desde una perspectiva igualitaria con ninguna otra nación, si no era, la misma Latinoamérica, una región unificada por un mismo espíritu. Bolívar lo afirmaba con las siguientes palabras:
“Nosotros no podemos vivir sino de la unión. España ha sido eliminada, pero no debe ser destruido el imperio, la unión creada por ella. Una nueva unión que tenga como base la cultura heredada y que, al mismo tiempo, ponga fin a las injusticias que hicieron execrable la unión bajo España. Una nueva unión, no ya creada por la fuerza, sino por el mutuo consentimiento de todas las naciones americanas y de cada uno de los hijos de éstas. ${ }^{34}$

Y sin embargo, en la realidad, las utopías se desbaratan. Las nuevas naciones que, como lo anticipaba también Bolívar, no pueden ser iguales a los grandes modelos que les sirven de arquetipo. No basta copiar las constituciones e instituciones políticas de Inglaterra, Francia y los Estados Unidos para hacer de esta parte de América naciones semejantes a ellas. ¿A dónde volver los ojos? ¿En dónde encontrar los modelos apropiados para las nuevas naciones hispanoamericanas? En ellas mismas, en la propia realidad. En esa realidad ya descubierta y exhibida por aquellos grandes precursores de la independencia

32. Ibídem, p. 132.

33. Ibídem, pp. 133-134.

34. Ibídem, pp. 134-135. 
iberoamericana; aquella realidad conocida por Bolívar y que en vano había luchado por mantener. ${ }^{35}$

Esto es indicativo de lo que el latinoamericano debe ejecutar para conseguir un espíritu más equilibrado. Dónde buscar las soluciones a las constantes problemáticas que se viven. Pues como afirma Zea, "las soluciones hay que buscarlas en nosotros mismos, en nuestra realidad (...) ¡Hay que contar con la realidad; de otra manera sólo planearemos utopías!"36 Por tanto pues, "había que contar con la propia realidad, cierto, pero contar con ella para transformarla, para hacerla distinta de lo que era. Y para ello era menester arrancarse, con toda la brutalidad que fuese precisa, la herencia recibida, el pasado español que los impedía ser otra cosa que pueblos a la zaga del progreso que animaba al mundo moderno. Para ellos, era menester adoptar las nuevas ciencias, la nueva concepción práctica del mundo y de la vida que con tanta prestancia llevaban los pueblos sajones." ${ }^{37}$

De ahí que el cambio cultural que se debe ir construyendo, deba incorporar el trabajo humano como una herramienta de cambio, una herramienta que aporta tremendamente a la superación de todo desequilibrio económico y por ende, social. Aunque esto es implique una lucha contra corriente, porque históricamente, había sido incorporado en Hispanoamérica con características eminentemente contrarias; ya que:

El trabajo en esta América, lejos de ser un instrumento de prosperidad, ha sido y es visto como algo degradante. Punto de vista heredado de la colonia, ya que el español hizo recaer el mismo en los grupos sociales que consideraba inferiores, los indígenas y los mestizos. El indio y el mestizo eran vistos como castas inferiores, degradadas. El indio era inferior, pero aun lo era más el mestizo. El mestizo -dice José Victorino Lastarria- le condenaba a la desgracia de ser el paria de la sociedad. Su condición era peor que la del indígena. $Y$ por ser inferior fue condenado, junto con el indio, el negro, el mulato y toda raza de color y mezcla a los trabajos más duros y degradantes. Por su degradación estaban condenados a los trabajos más violentos. A aquellos trabajos, precisamente, que estaban haciendo la grandeza de los hombres de los nuevos pueblos, de las nuevas naciones. ${ }^{38}$

Por ello, Zea, citando a Bilbao nos dice que "nos hemos emancipado de España políticamente; ahora debemos hacerlo mentalmente. Una segunda revolución debe seguir a la política, la revolución mental. Y el arma para esta nueva revolución lo será la educación." ${ }^{39}$ Al pueblo, no se le puede pedir que sepa lo que nunca ha conocido. Las instituciones republicanas, los hábitos de trabajo 
que admiramos en el sajón, la libertad de conciencia serán ajenas a nuestros pueblos si no se les educa para ello. Hay que educar, por tanto, para la libertad; hacer mentes libres que den sentido y posibilidades a las instituciones libres que queremos para los hispanoamericanos.

Ahora bien, ni el indio ni el mestizo son inferiores a otras razas; son simplemente hombres en una determinada situación que puede y debe ser transformada para hacer de ellos grupos activos al servicio de la grandeza total de sus naciones. Es más, "de su generosa actitud saldrán las filosofías políticas que en el Perú y en los Andes en general ven en los indígenas, no ya un fuerza negativa y frenadora, sino un gran ejemplo de realización social, por lo que han sido y la posibilidad de lo que pueden llegar a ser." 40

En definitiva, pues, de lo que se trata es de ejecutar un giro, una vuelta a la realidad propia de los pueblos latinoamericanos, que haga surgir el nuevo espíritu, cuya naturaleza propia hace que el mismo ser latinoamericano no se sienta ni más ni menos que otras culturas, sino alguien que es simplemente hombre, y, que por tanto, nada de lo que a cualquier humano le competa, tampoco al latinoamericano le sea extraño. De ahí que Zea afirme que:

En fin, de esta nueva vuelta a la realidad iberoamericana, una vuelta que ha eliminado los errores de las realizadas en el pasado, ha surgido la conciencia, que ahora se expresa en nuestros días, de incorporación a la universalidad de lo humano, asimilándolo y aportando lo que como humano le es propio. Y, con ello, el encuentro con lo que de común tienen los hombres entre sí, con independencia de sus circunstancias naturales y sociales. Haciendo a un lado ya cualquier sentimiento de inferioridad frente a culturas y razas, conscientes de que se es, simplemente, hombre y, como tal, con posibilidades e impedimentos circunstanciales que pueden y debe ser vencidos. ${ }^{41}$

\subsection{La mayoría de edad del latinoamericano}

La realidad se impone, y el sueño de ejecutar un cambio de paradigma para el espíritu latinoamericano, se ha quedado en eso, en un sueño. No obstante, convertir ese sueño en utopía, sigue siendo algo alentador. En esta perspectiva, la tarea sigue llamando a todos aquéllos y aquéllas que han nacido en esta parte del mundo, a hacer todo lo que esté al alcance para transformar la realidad. Cambiar ese espíritu es algo que debe ejecutarse ya que sólo eso hará que el futuro sea de Latinoamérica; Zea lo afirma diciendo que:

El siglo XX encuentra a una Latinoamérica que, habiéndose emancipado políticamente de España y Portugal, mantiene los hábitos y costumbres impuestos por la colonia. Oligarquías y dictaduras, como la de Díaz en 
México, se enseñorean sobre el conjunto de pueblos que han surgido al desprenderse de las metrópolis ibéricas. El ideal liberal que aspiraba a hacer de estos pueblos naciones semejantes a las que encabezaban la marcha del progreso se ha frustrado y surgen sólo caricaturas detrás de las cuales se mantiene intocado el mundo que se decía modificar. ${ }^{42}$

Ahora bien, el hecho de que se tomen ideas de otros es algo obvio. Que se tomen las ideas prestadas de otros, de aquellos que de alguna manera han pensado más y mejor que nosotros, ha sido algo necesario en la cultura. Sartre ha afirmado que unos pocos generan el logos y que los demás, que son la gran mayoría, lo tomamos prestado. ${ }^{43}$ La cita es mucho más dura, sobre todo, porque entre líneas denigra al indígena y lo coloca en una situación de dudosa procedencia y ubicación en la perspectiva de la esencialidad humana. No obstante, tomar prestadas las ideas de otros, no es malo. Al contrario, es bueno. Lo malo es tomar prestadas ideas que son insensatas, negativas o mediocres. Pero tomar prestadas las buenas ideas, las más sublimes, las más sugerentes y englobantes; $y$, desde ellas, explicar nuestra situación e intentar interpretar nuestra realidad, nos conduce inexorablemente a lo que llamamos filosofía. Eso es hacer filosofía autóctona. ${ }^{44}$ Pensar profunda y conscientemente nuestra realidad y nuestros problemas, e intentar aportar a la resolución de los mismos.

Por nuestra parte, pues, creemos que lo que queda como reto es descubrir en cada autor cuáles han sido las ideas prestadas y luego ver qué aportes han tendido a la solución de los problemas en Latinoamérica. Obviamente, habrá autores que sólo tomaron prestadas las ideas, no para interpretar la realidad e intentar resolverla, sino que se quedaron en un mundo suprasensible, para desde ahí, gozarse olvidándose que la filosofía es en realidad una búsqueda de concretar mayores niveles de vida, tanto en calidad como en cantidad, para todos y todas. Cuando se reduce la filosofía a la actividad de sólo copiar ideas, esta actividad ya no es filosofía, sino una actitud particular que se quedó en la simple búsqueda pero que no dio el salto cualitativo de pasar de la razón, del logos a la praxis y de ésta a la realidad. Leopoldo Zea lo afirma diciendo que la filosofía "surgida frente a la urgencia de las circunstancias, se hace en la vida pública, en los campos de batalla, en los destierros o en las cárceles. De Europa, de la filosofía europea, se toman sistemas e ideas, pero se les retuerce, se les adapta y de ese retorcimiento y adaptación va surgiendo la filosofía que con el historicismo de nuestros días se podrá calibrar en su justo valor. ${ }^{45}$ En esta perspectiva, Leopoldo Zea, citando a Alejandro Korn afirma que:

42. Ibídem, p. 164.

43. Cfr. ZEA, Leopoldo, Filosofía americana como filosofía sin más, Fondo de Cultura Económica, México, 1963. P. 9. El texto citado por Zea dice así: "No hace mucho tiempo, la tierra estaba poblada por dos mil millones de habitantes, es decir, quinientos millones de hombres y mil quinientos millones de indígenas. Los primeros disponían del Verbo, los otros lo tomaban prestado".

44. Cfr. ZEA, Leopoldo, Filosofía americana como filosofía sin más, Fondo de Cultura Económica, México, 1963.

45. Zea, L., La Esencia de lo Americano. Op.Cit. p. 175. 
No podemos continuar con el positivismo, agitado e insuficiente, y tampoco podemos abandonarlo. Es preciso pues incorporarlo como un elemento subordinado a una concepción superior (...) Porque importa ante todo emancipar al hombre de su servidumbre y devolverle su jerarquía como creador de la cultura, destinada a actualizar su libertad intrínseca: es propio del hombre poner en la vida un valor más alto que el económico". El positivismo sólo había justificado el egoísmo de grupos sociales que en nombre del progreso trataban de mantener su predominio sobre grupos más débiles, originando oligarquías y dictaduras deshumanizadas. ${ }^{46}$

Ahora bien, para concluir esta primera parte, hay que afirmar que como ejemplo concreto de lo humano en su expresión filosófica lo había sido el europeo en sus diversas modalidades, griega, francesa, alemana, inglesa, etc.. Un ejemplo más de esta humanidad lo era también el hombre en sus expresiones americanas y sus modalidades nacionales. Uno y el mismo hombre, en diversas pero no menos ineludibles situaciones era el que se había expresado en la filosofía de ayer y que seguiría expresándose en la filosofía de hoy. En este sentido, como Zea afirma:

Experiencias humanas, concretas, elevadas a la universalidad de lo humano por excelencia; universalidad que se expresaba en la similitud y originalidad de esas experiencias en relación con las de otros hombres en circunstancias que por distintas que fuesen no lo eran tanto que no pudiesen ser comprendidas por otros. Detrás de lo circunstancial y concreto, estaba siempre el hombre. El hombre se encontraba con el hombre, lo concreto con lo universal. La filosofía europea había aportado al mundo sus experiencias la latinoamericana podía también aportar las suyas. Y esta vez sin tapujos, timideces, ni sentimientos de inferioridad. Por circunstancias que fuesen sus experiencias, no por ello dejaban de ser experiencias humanas y por ello al alcance y comprensión del único donador de universalidad, el hombre. El hombre de aquí, de allá, de cualquier parte. El hombre concreto y universal al igual que las expresiones de su pensamiento. ¿Filosofía latinoamericana? No, filosofía sin más, que lo latinoamericano se dará ineludiblemente. Será la respuesta de la filosofía latinoamericanas sobre su propia existencia. ${ }^{47}$

Leopoldo Zea ha significado, con su filosofía, una especie de arribo a la mayoría de edad de la filosofía latinoamericana, respecto de su hermana mayor, la filosofía europea.

Lo que se ha visto con Zea es aquella vieja preocupación de que el conocimiento que llamamos americano y su relación con la cultura universal. Como se ha 
visto, a lo americano se le ha dado una connotación más amplia, rescatando para América latina el nombre que la América sajona había privatizado para sí: América para los americanos.

Con Leopoldo Zea llegamos al reconocimiento que los próceres de la independencia y de la emancipación mental, se llamaron a sí mismos americanos. Por tanto, americanos son San Martín, Bolívar, Hidalgo, Sarmiento, Lastarria, Montalvo, Bello, Mora, Delgado, Cañas, Del Valle, etc.,

Ahora bien, con ellos, se reconoce que la construcción de la identidad latinoamericana es una acción presente, una acción que sólo puede darse con el concurso y participación de todos los pueblos latinoamericanos, además de ser una realidad abierta al presente y también al futuro. En esta perspectiva, el papel del filósofo es optar por el pueblo y unir a él su vida. Sin esta conexión con el pueblo, su filosofar serán palabras huecas, sin raíces. De este modo, la función del filósofo se pone en cuestión. No puede filosofar por su cuenta y al margen del pueblo; de ahí que ese optar del filósofo por el pueblo, no sólo es una opción discursiva que pueda hacerse desde el escritorio u oficina con aire acondicionado o desde la simple cátedra universitaria; eso en parte, pero también, y sobre todo, optar por el estar allá donde se juega el ser y quehacer de la vida de las mayorías; allá donde se establecen las encrucijadas prácticas de la historia y de la vida. Allá donde las contradicciones son más álgidas y a veces casi irracionales. Esto es lo que han hecho, desde mi punto de vista, filósofos como Leopoldo Zea y Alberto Masferrer.

\section{BIBLIOGRAFÍA}

Beorlegui, Carlos, Historia del pensamiento filosófico latinoamericano, una incesante búsqueda de la identidad. Universidad de Deusto, España, 2004.

Casaús Arzú, Marta E. y Teresa García G., Las redes intelectuales centroamericanas: Un siglo de imaginarios nacionales (1820-1920), Guatemala, 2005.

Díaz Genis, Andrea; La construcción de la identidad en América Latina; Editorial Nordan-Comunidad, Montevideo, Uruguay. 2005.

Zea, Leopoldo, La esencia de lo americano, Editorial Pleamar, Buenos Aires, Argentina, 1971.

Zea, Leopoldo, La filosofía americana como filosofía sin más, Fondo de Cultura Económica, México, 19éxico, 1963. 